\section{The footballer's fracture}

\author{
H R Cattermole, J R W Hardy, P J Gregg
}

\begin{abstract}
Objective-To describe the typical tibial diaphyseal fracture ("footballer's fracture") and to clarify the circumstances and mechanism of the injury.

Methods-In an attempt to obtain a detailed analysis of the types of injury suffered, and thereby highlight areas for prevention, 100 consecutive adult football players with a tibial diaphyseal fracture were studied prospectively. Details of the circumstances and mechanism of injury were collected using a questionnaire (response rate $85 \%$ ). Treatments depended on the Gustilo classification, displacement, and axial stability. Long term follow up was performed until clinical healing to define the overall prognosis.
\end{abstract}

Results- $61 \%$ of players suffered a fracture of both the tibia and the fibula. Ninety five percent of the tibial fractures were transverse or short oblique and were caused by impact during a tackle. Radiographic evidence of bridging callus was better than a classification of the bony injury for predicting weeks to clinical healing. The delayed union and non-union incidence following this injury is low. One patient suffered symptomatic shortening. One patient suffered symptomatic angulation and two patients with nonunion required bone grafting.

Conclusions-Tibial fracture is an expensive injury. It prevents a young population from being employed and takes up valuable NHS resources. As $85 \%$ of players were wearing shin guards, it is likely that improvements in shin guard design could reduce the rate of tibial fracture.

(Brf Sports Med 1996;30:171-175)

Key terms: football injuries; tibial fracture; protective devices; shin guards

Orthopaedic Surgery,

Hospital of St Cross,

Barby Road,

Rugby CV22 5PX,

United Kingdom

H R Cattermole

University Department of Orthopaedic

Surgery,

Glenfield General

Hospital,

Groby Road,

Leicester LE3 9QP,

United Kingdom

J R W Hardy

P J Gregg

Correspondence to:

J R W Hardy FRCS

Accepted for publication

20 February 1996 In the United Kingdom it is estimated that $10 \%$ of the adult population play football at least once a year. ${ }^{1}$ Football is responsible for $3.5-10 \%$ of all injuries treated in hospital, ${ }^{2}$ but this may reflect the popularity of the sport rather than its dangers.

The majority of football injuries are to the lower limbs, ${ }^{3}$ comprising $70-88 \%$ of injuries in published studies. ${ }^{4-7}$ The ankle and the knee are the most frequent site of injury. ${ }^{8-10}$ The commonest types of injury are sprains $(19 \cdot 4 \%)$, strains $(27 \cdot 8 \%)$, and contusions $(35 \cdot 2 \%){ }^{4}$

Fractures comprise $2-20 \%$ of reported footballing injuries, depending on the source of the data. ${ }^{491112}$ They are responsible for a disproportionate amount of disability and medical costs ${ }^{12}$ and lead to the highest number of mean work days lost when compared to other injuries. ${ }^{13}$ Lower extremity fractures form approximately one third of football fractures $^{6} 14$ and are particularly expensive. One study calculated that although tibial and/ or fibular fractures accounted for only $13 \%$ of major injuries in football, they were responsible for $30 \%$ of days lost from work. ${ }^{15}$

Tibial diaphyseal fracture is infrequently reported in the literature on football injuries, ${ }^{81617}$ probably because the numbers are masked by the huge numbers of strains, sprains, and contusions which occur. The mechanism of injury has to our knowledge not been studied before.

The aim of this study was to describe the typical "footballer's fracture" and to clarify the circumstances and mechanism of the injury. From this information, it is hoped to be able to identify potential ways to reduce or prevent this injury.

\section{Methods}

At Leicester Royal Infirmary, between 1992 and 1994 an average of 50 tibial diaphyseal fractures each year could be attributed to playing football (total population served = 918000 ), making football the commonest cause of adult tibial diaphyseal fracture (36\%).

One hundred consecutive football players with tibial fracture were identified and studied prospectively by questionnaire either at the time of admission or through the post soon after the fracture. Details of the circumstances and mechanism of injury were collected using this questionnaire. Initially, 67 questionnaires were returned: those who did not respond were sent a second postal questionnaire, which (85\% overall response). All 100 players underwent a thorough physical examination and their radiographs were analysed on admission.

Fractures were classified according to the AO/ASIF group and Gustilo classifications. ${ }^{1819}$ Injuries involving the knee, upper tibial metaphysis, lower tibial metaphysis, and ankle were excluded. Measurements of tibial length, and the height of the tibial and fibular fractures above the ankle were taken from the anteroposterior and lateral radiographs following reduction of the fracture and were not adjusted for the $8 \%$ magnification that occurs with the standard radiograph (figure).

Immobilisation of the fracture depended on the Gustilo type, displacement, and axial stability on examination under anaesthetic. In some cases a random allocation of treatments based on the considerations above was resulted in a further 18 replies being received 
performed as part of a separate study not further discussed in this paper.

During follow up, maximum angulatory deformity was calculated from anteroposterior and lateral radiographs taken at $90^{\circ}$ to each other, using the square root of the sum of both angles squared. Clinical healing was defined as pain-free full weight bearing without support and no fracture site tenderness or pain on stressing by bending. Delayed union was defined as no sign of clinical healing after 20 weeks, and non-union was defined as no sign of clinical healing at or after six months.

\section{Results}

All the players were amateur, and all but one were male. Their average age was 26 years (range 16-48); 73 broke their right leg, and 27 their left.

Local league games and county level matches accounted for $70 \cdot 5 \%$ of injuries. "Friendlies", charity matches, and casual kickarounds accounted for the next largest group of tibial fractures (16.5\%) (table 1 ).

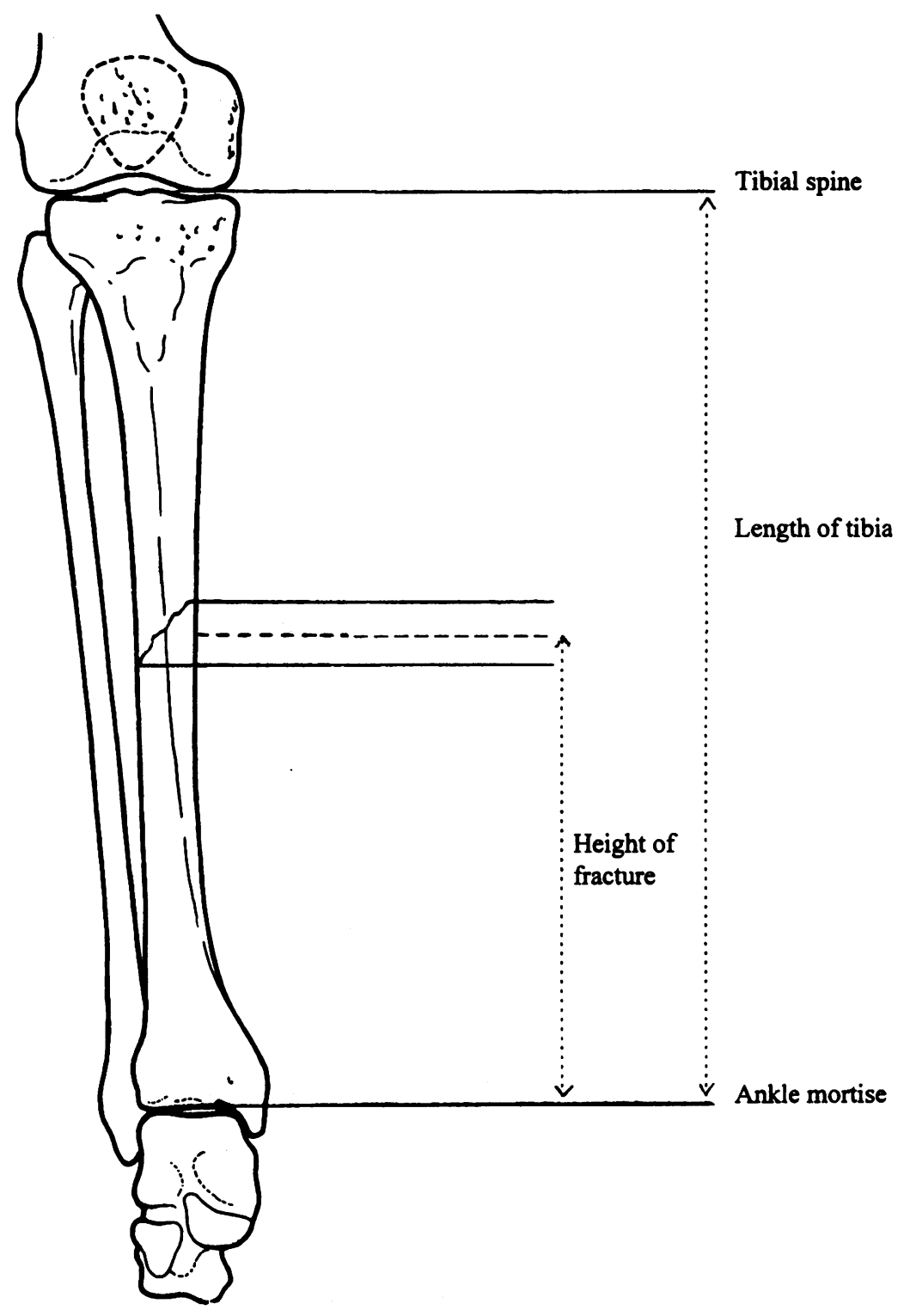

Tibial measurements
Table 1 Type of game

\begin{tabular}{lcr}
\hline Type of game & Number & Percent \\
\hline Local & 50 & $58 \cdot 8$ \\
County & 10 & $11 \cdot 7$ \\
Semi-professional & 2 & $2 \cdot 4$ \\
5-a-side & 2 & $2 \cdot 4$ \\
Training & 7 & $8 \cdot 2$ \\
Other & 14 & 16.5 \\
Total & 85 & $100 \cdot 0$ \\
\hline
\end{tabular}

Not surprisingly, $91.8 \%$ of injuries happened on grass; $87 \%$ of footballers were wearing footwear appropriate for the playing surface (table 2 ).

Thirty six per cent of injuries occurred during matches without a referee or with one not registered with the English Football Association (table 3).

Players in all positions sustained tibial fractures. All fractures occurred during tackling, with $12(14 \cdot 1 \%)$ doing the tackling, $28(32.9 \%)$ being tackled, and $45(53 \%)$ involved in a 50/50 tackle. Thirty three players $(38.8 \%)$ thought that their injuries resulted from illegal tackles, yet only three players (3.5\%) were booked.

Only five patients had simple spiral fractures, caused by pure torsion. The rest (95\%) reported an impact as the mechanism of injury, mostly $(56.5 \%)$ resulting from a kick on the shin from in front (table 4). These players had transverse, short oblique, or comminuted fractures. Seventy four patients suffered simple two part fractures. Twenty three had fractures that included a third butterfly fragment. Three suffered comminution with more than three fragments (table 5)

In accordance with Fédération International de Football Associations rules, which stipulate that shin guards are worn during club matches, $83.5 \%$ of players were wearing shin guards. Of the remainder, all but one player were in a kickaround or training, indicating good compliance with the rules. Damage at the point of impact, with cracking or snapping, occurred in $16.9 \%$ of the shin guards.

Ninety three tibial fractures were closed. Seven were open fractures, one Gustilo type I, and six Gustilo type II.

No fractures occurred in the upper third of the diaphysis. Sixty patients had fractures in the middle third and 40 had fractures in the lower third of the tibial diaphysis. The mean height of fracture above the ankle for players suffering a direct injury was $14.2 \mathrm{~cm}$ (range 5.5 to $23.5 \mathrm{~cm}$ ) and the mean length of the tibia was $41.6 \mathrm{~cm}$ (range 34.9 to $48.8 \mathrm{~cm}$ ).

Initial treatments involved 46 patients who underwent plaster casting in clinic: 24 who required manipulation under anaesthetic and plaster cast, 21 who had external fixation for unstable fractures or compound fractures, and nine who received reamed, locked, intramedullary nailing.

A change in treatment occurred in six cases. One patient insisted on receiving a dynamic compression plate. Three patients lost the original position achieved after plaster cast application in clinic and required late 
Table 2 Type of playing surface

\begin{tabular}{lrrlll}
\hline Surface & No & Percent & $\begin{array}{l}\text { Cleated } \\
\text { football } \\
\text { boots }\end{array}$ & $\begin{array}{l}\text { Training } \\
\text { shoes }\end{array}$ & $\begin{array}{l}\text { Artificial } \\
\text { surface } \\
\text { shoes }\end{array}$ \\
\hline Hard grass & 26 & $30 \cdot 6$ & 21 & 4 & 1 \\
Soft grass & 50 & $58 \cdot 8$ & 48 & 2 & \\
Grass (unspecified) & 2 & $2 \cdot 4$ & & 2 & 1 \\
Artificial grass & 3 & $3 \cdot 5$ & & 2 & 2 \\
Hard surface & 4 & $4 \cdot 7$ & & 14 & \\
Total & 85 & $100 \cdot 0$ & 69 & & \\
\hline
\end{tabular}

manipulation under anaesthetic and replastering. One patient had unacceptable shortening following initial manipulation under anaesthetic and plaster cast, and was converted to intramedullary nailing. In one patient who received manipulation under anaesthetic and plaster cast, position was lost after a fall and external fixation was done.

A total of 748 days was spent in hospital by 100 patients on first admission following fracture (mean 7.48 days, $95 \%$ confidence interval 5.59 to 9.37 days). Ten patients required further admissions for a change of treatment or removal of metal. This accounted for a further 78 days in hospital.

Of the 100 patients admitted, $30 \%$ were unemployed at the time. Twenty two patients had desk jobs, 20 had light manual occupations, 19 had heavy manual occupations, and nine had occupations that required climbing. Data on return to work were available for 56 patients. Median time off work was 109 days (range 13 to 377). More than 6667 days of employment were lost by this group of 100 patients.

Four patients were lost to follow up before clinical healing could be judged. One patient died of leukaemia. Two patients were transferred to the care of another hospital. One patient failed to return for follow up appointments in clinic and was not traceable. Data for outcome measures come from 96 of the 100 patients identified.

Time (weeks) to initial callus bridging on radiographs $\left(R^{2}=0.5781\right)$ was better than the AO/ASIF classification $\left(R^{2}=0.0684\right)$ for predicting weeks to clinical healing. The mean time to clinical healing was 15.05 weeks $(95 \%$ confidence interval 11 to 16.48 weeks). Eleven patients were identified as having delayed union and three of these had not healed by 24

Table 3 Status of referee

\begin{tabular}{llc}
\hline Status of referee & Number & Percent \\
\hline FA Registered & 54 & 63.5 \\
Not registered & 17 & $20 \cdot 0$ \\
No referee & 13 & 15.3 \\
Unknown & 1 & 1.2 \\
Total & 85 & $100 \cdot 0$ \\
\hline
\end{tabular}

Table 4 Reported mechanism of injury

\begin{tabular}{lcr}
\hline Mechanism & Number & Percent \\
\hline Impact & & \\
Anterior & 48 & $56 \cdot 5$ \\
Medial & 17 & $20 \cdot 0$ \\
Lateral & 14 & $16 \cdot 5$ \\
Posterior & 1 & $1 \cdot 1$ \\
No impact & 5 & $5 \cdot 9$ \\
Total & 85 & $100 \cdot 0$ \\
\hline
\end{tabular}

Table 5 Secondary complications

\begin{tabular}{ll}
\hline Compartment syndrome & 7 \\
Common peroneal nerve neuropraxia & 2 \\
Hypertrophic non-union & 3 \\
Screw removal for external fixation pin site infection & 2 \\
Locking screw failure & 1 \\
Refracture & 1 \\
\hline
\end{tabular}

weeks (non-union). Two of the latter received bone grafts to assist healing.

Of 17 patients who healed with some shortening, only one, with $2.5 \mathrm{~cm}$ shortening, was symptomatic. The median value for shortening was $4 \mathrm{~mm}$ (range 1 to 25 ).

Only 26 patients showed angular deformity after healing. The median angular deformity was $8^{\circ}$ (range $1^{\circ}$ to $17^{\circ}$ ). One patient was symptomatic with a varus deformity of $12^{\circ}$ at $12.5 \mathrm{~cm}$ above the ankle joint.

Thirteen patients suffered secondary complications of their treatment. These are given in table 5 .

\section{Discussion}

A tibial fracture is an unusual but by no means uncommon injury in football. In numerical terms, less serious injuries predominate, but by extrapolating the numbers of players treated at Leicester Royal Infirmary to the United Kingdom as a whole, we estimate that amateur football players sustain over 2700 tibial fractures a year.

There are no other published series that have looked specifically at tibial fractures in football players. The results of our study suggest that in most players the injury is not severe and that few complications occur if treatment appropriate to the pattern of injury is applied.

Return to work as an outcome measure for a subpopulation of patients does not allow comparison with other series because of the $30 \%$ unemployment rate and the many different types of work, which had a confounding influence. The number of hospital days taken up by this group is a more valuable measure, particularly for cost analysis. The estimated annual cost for managing these patients locally, including the cost of hotel services, theatre time, statutory sick pay for those employed, and outpatient visits was $£ 126000 .^{20}$ Extrapolated to the United Kingdom population this represents a minimum cost of $£ 7 \cdot 7$ million every year.

For the individual player, the effects of a tibial fracture can be devastating, including long periods of time off work, unemployment, or permanent disability. Furthermore, many players interviewed at Leicester Royal Infirmary thought that their injury was preventable had there been tighter referee control on the game.

In England, football is played by approximately 1.5 million adults, of whom only 2500 are full time professionals. The senior non-professional and semiprofessional clubs are organised in a pyramid system, with 22 clubs at the top, 200 clubs in the middle, and 800 clubs at the bottom (county) level; the remaining 39000 clubs compete locally. There are 700 clubs in Leicestershire, with approximately $25-30$ playing members per club 
(D Barber, English Football Association, personal communication).

It is not surprising that tibial fractures occurred most commonly during games at local level because of the overwhelming numbers involved. Nevertheless, in higher leagues relatively few fractures occur, ${ }^{2}$ despite games tending to be faster, more aggressive, and with more bodily contact. ${ }^{21}$ This can be explained partly by differing levels of fitness, training, and experience. ${ }^{2}$ The more professional players are therefore to a certain extent protected against injury.

As every league game should have a Football Association approved referee, ${ }^{22}$ the standard of refereeing may have some bearing on the injury rate. For example, a good referee will keep the game under tight control, and will not allow dangerous behaviour to occur unchecked. However, our results show that this ideal is not always achieved. Thus, for example, it is noteworthy how few bookings resulted from what must have been fairly violent tackles. The reasons for this discrepancy are unclear. It may be that no infringement of the rules was felt to have taken place, or that the situation was not fully appreciated by the referee. There may be scope to improve referee education and effectiveness in this area. Undoubtedly there is also some bias by the injured player against the person causing the injury, and a desire for retribution which may affect their view of the incident; perhaps we should be pleasantly surprised by the number of players who thought they had been tackled fairly!

Five-a-side matches, "friendlies", and training sessions together account for more than $a$ quarter of tibial fractures. It is conceivable that this relatively high level of injuries could be a consequence of having no referee. As these types of game are difficult to influence by legislation, player education may be the only means of improving safety.

We were surprised to find that $87 \%$ of players were wearing suitable footwear, as we were expecting many more torsional injuries through, for example, wearing training shoes on grass, or from playing on artificial surfaces. Work has been carried out by others in the areas of foot/ground traction, and the effects of different surfaces on the likelihood of falling. ${ }^{23}{ }^{24}$ As only $5 \%$ of our players were injured simply through falling, we have not studied this further.

The different patterns of tibial fracture result from differences in the magnitude of the load on the bone, the rate of loading, and the type of loading. ${ }^{25} 26$ Seventy nine fractures were low energy, minimally displaced transverse fractures with or without a butterfly fragment (A0/ASIF 42A3, 42B2, 42B3). These were caused by simple three point bending. The 14 comminuted and oblique fractures arose as a result of three point bending of a leg that was under compression at the time (A0/ASIF 42A2, 42C 1, 42C3).

While the AO/ASIF classification correlated with the described mechanism of injury, we found a poor correlation between this classification and clinical healing. This probably represents the poor accuracy and large variability of the measure "clinical healing" rather than the classification itself. Even the correlation between weeks to initial callus bridging and weeks to clinical healing was poor. This seemed not only due to the cases of hypertrophic non-union, in which the callus bridge was seen to break, but also because of the inaccuracy of the end point measure.

There have been few previous studies on the design, use, and effectiveness of shin guards. Backous et al found that $10.5 \%$ of players not wearing shin guards sustained a leg injury, compared with $2 \cdot 2 \%$ of players who were wearing them. ${ }^{4}$ Ekstrand and Gillquist stated that all traumatic leg injuries occurred in those wearing "inadequate or no" shin guards, and consequently recommended their compulsory use. ${ }^{27} 28$ The same conclusions were drawn by Roaas and Nilsson ${ }^{15}$ and Berger-Vachon et al, ${ }^{29}$ but no follow up epidemiological studies have been done to assess the effect of wearing them.

Although in our study, shin guard use was widespread, surprisingly $85 \%$ of the players who were injured while wearing shin guards suffered anterior or medial impacts, which is the area covered by the shin guard. Currently available shin guards are only effective as protection against abrasions, contusions, and lacerations. They are incapable of withstanding an impact sufficient to cause a tibial fracture. ${ }^{30}$ They also have little stiffness to bending, which means that the force of a kick is not transmitted along the length of the tibia, effectively resulting in point loading. If a guard is too stiff, however, then there is a danger of transmitting the impact energy to the knee and ankle joints, resulting in joint injury which would be catastrophic for the sports player.

Of the guards we studied $83.1 \%$ remained undamaged by the impact. Damage to a structure during an impact is an indicator of energy absorption by that structure. A shin guard which is capable of absorbing some of the impact energy, and thus reducing the amount transferred to the tibia, would be valuable in prevention of tibial fractures caused by this mechanism. Obviously the protective effect would be at the expense of the structural integrity of the guard.

We believe that further developments in shin guard technology could prevent many of the low energy injuries seen in our population. Using the data from this study about the mechanism and distribution of the injuries, and the range of tibial dimensions, shin guards could be designed using materials capable of absorbing some of the impact energy. This may mean that the shin guard would have a limited lifespan, which would have to be reflected in the cost. This is an area we are now investigating.

We would like to thank the Orthopaedic Consultants at Leicester Royal Infirmary for allowing us to study their patients. We are also grateful to Rugby NHS Trust and the BOA Wishbone Trust for financial support. We would like to acknowledge Dr C Soutis of Leicester University Department acknowledge Dr C Soutis of Leicester University
of Material Engineering for helpful discussions.

1 Matheson J. Participation in sport: a study carried out on behalf of the Department of the Environment as part of the 1987 
General Household Survey. OPCS Social Survey Division, Series GHS No 17 suppl B. London: HMSO 1991

2 Ekstrand J, Gillquist J, Möller M, Öberg B, Liljedahl SO. Incidence of soccer injuries and their relation to training and team success. Am F Sports Med 1983;11 63-7.

3 Pardon ET. Lower extremities are site of most soccer injuries. Phys Sports Med 1977;5:43-8.

4 Backous DD, Friedl KE, Smith NJ, Parr TJ, Carpine WD. Soccer injuries and their relation to physical maturity. $\mathrm{Am}$ f Dis Child 1988;142:839-42.

5 Engstrom B, Johansson C, Törnqvist H. Soccer injuries among elite female players. Am f Sports Med 1991; 19:372-5.

6 Maehlum S, Daljord OA. Football injuries in Oslo: a one year study. Br f Sports Med 1984;18:186-90.

7 Watson AW. Incidence and nature of sports injuries in Ireland. Analysis of four types of sport. Am 7 Sports Med 1993;21:137-43.

8 Bass AL. Injuries of the leg in football and ballet. Proc $R$ Soc Med 1967;60:527-30.

9 Ekstrand J, Roos H, Tropp H. Normal course of events amongst Swedish soccer players: an 8 year follow-up study. Br $\mathcal{F}$ Sports Med 1990;24:1 17-9.

10 de Loes M. Medical treatment and costs of sports-related injuries in a total population. Int $\mathcal{f}$ Sports Med 1990;11:66-72.

11 Keller CS, Noyes FR, Buncher CR. The medical aspects of soccer injury epidemiology. Am $\mathcal{F}$ Sports Med 1987; 15:230-7.

12 Pritchett J W. Cost of high school soccer injuries. Am $\mathcal{f}$ Sports Med 1981;9:64-6.

13 Harlan LC, Harlan WR, Parsons PE. The economic impact of injuries: a major source of medical costs. $\mathrm{Am} \mathcal{F}$ Public Health 1990;80:453-9.

14 Ekstrand J, Gillquist J. The frequency of muscle tightness and injuries in soccer players. Am $\mathcal{f}$ Sports Med and injuries

15 Roaas A, Nilsson S. Major injuries in Norwegian football. Br $\mathcal{F}$ Sports Med 1979;13:3-5.
16 Agre JC. Avoiding this season's common soccer injuries. $f$ Musculoskel Med 1987;4:29-38.

17 Gunther SF. An avoidable soccer injury. 7 Sports Med. 1974;2:167-9

18 Müller ME, Allgbwer $M$, Schneider $R$, Willenegger $H$. Manual of internal fixation, 3rd ed. Berlin: SpringerVerlag, 1991

19 Gustilo RB, Merkow RL, Templeman D. Current concepts review - the management of open fractures. $\mathcal{F}$ Bone foin Surg Am 1990;72-A:299-303.

20 Hardy JRW, Richardson JB, Gregg PJ. The footballer's fracture. F Bone foint Surg $\mathrm{Br}$ 1994;76-B(suppl I \& III): $141-2$.

21 Ekblom B. Applied physiology of soccer. Sports Med 1986;3:50-60.

22 The Football Association. The referee's chart and player's guide to the laws of association football. London: Macmillan,

23 McCarthy P. Artificial turf. does it cause more injuries? Physician Sports Med 1989;17:158.

24 Ekstrand J, Nigg BM. Surface-related injuries in soccer. Sports Med 1989;8:56-62.

25 Martens M, Van Audekercke R, De Meester P, Mulier JC The geometrical properties of human femur and tibia and their importance for the mechanical behaviour of these bone structures. Arch Orthop Trauma Surg 1981;98: 113-20.

26 Kramer $M$, Burow K, Heger A. Fracture mechanism of lower legs under impact load. Proceedings of the 17th STAPP Car Crash Conference. Warrendale PA: Society of Automotive Engineers, 1973:81-100.

27 Ekstrand J, Gillquist J, Lijedahl SO. Prevention of soccer injuries. Supervision by doctor and physiotherapists. $\mathrm{Am}$ 7 Sports Med 1983;11:116-20.

28 Ekstrand J, Gillquist J. The avoidability of soccer injuries. Int $\mathcal{F}$ Sports Med 1983;4:124-8.

29 Berger-Vachon C, Gabard G, Moyen B. Soccer accidents in the French Rhone-Alps soccer association. Sports Med 1986;3:69-77.

30 Philippens $M$, Wismans J. Shin guard impact protection. IRCOBI Proceedings 1989:65-76.

\section{Commentary}

This is a good paper studying a frequently overlooked, although common, sports injury which has enormous cost to the health service, individuals, and society as a whole. Having highlighted the problem the authors go on to try and identify potential risk factors and then the possibility of improving preventative measures. I look forward to their work on improving the efficacy of shin pads.

In view of recent litigation it is interesting the authors highlight the role of the referee in injury prevention and this study should be brought to the attention of the FA.

The authors rightly identify that this injury is not severe in the majority of cases as the mechanism is of low violence. Although not seen in this series I would like to mention the potentially disastrous complication of compartment syndrome that is more common following minimally displaced fractures. I have seen two players with completely infarcted anterior compartments following undisplaced fractures and in whom the symptom of increasing pain, despite adequate splintage, was ignored. This should not be allowed to occur. 


\section{Corrections}

In the paper by Quarrie et al in the December issue (volume 29, pages263-270) there were two uncorrected errors:

On page 264, right column, line 7, the sentence should read: "First class locks and loose forwards performed significantly better than did theirrespective second class peers on a vertical jump test."

On page 265 , right column the formula for momentum has been inverted. It should be as follows:

$30 \mathrm{~m}$

Time taken for sprint from standing start(s)

Player's body mass $(\mathrm{kg})$

In the paper by Cattermole et al in the June issue (The footballer's fracture; vol 30, pp 171-175), table 5 was accidentally omitted and the table labelled 5 should have been number 6 . The omitted table is reproduced here.

Table 5 AO/ASIF classifications

\begin{tabular}{|c|c|}
\hline AOIASIF classification & Number \\
\hline $\begin{array}{l}42 \text { A } 1.1 \\
42 \text { A } 1.2 \\
42 \text { A } 1.3\end{array}$ & $\begin{array}{l}3 \\
1 \\
1\end{array}$ \\
\hline $\begin{array}{l}42 \text { A } 2.1 \\
42 \text { A } 2.2 \\
42 \text { A } 2.3\end{array}$ & $\begin{array}{l}5 \\
2 \\
4\end{array}$ \\
\hline $\begin{array}{l}42 \text { A } 3.1 \\
42 \text { A } 3.2 \\
42 \text { A } 3.3\end{array}$ & $\begin{array}{l}25 \\
2 \\
31\end{array}$ \\
\hline $\begin{array}{l}42 \text { B } 1.1 \\
42 \text { B } 1.2 \\
42 \text { B } 1.3\end{array}$ & $\begin{array}{l}1 \\
1 \\
0\end{array}$ \\
\hline $\begin{array}{lll}42 & \text { B } 2.1 \\
42 & \text { В } 2.2 \\
42 & \text { В } 2.3\end{array}$ & $\begin{array}{l}0 \\
1 \\
2\end{array}$ \\
\hline $\begin{array}{l}42 \text { В } 3.1 \\
42 \text { В } 3.2 \\
42 \text { В } 3.3\end{array}$ & $\begin{array}{l}5 \\
1 \\
12\end{array}$ \\
\hline $\begin{array}{lll}42 & C & 1.1 \\
42 & C & 1.2 \\
42 & C & 1.3\end{array}$ & $\begin{array}{l}0 \\
0 \\
2\end{array}$ \\
\hline $\begin{array}{l}42 \text { C } 2.1 \\
42 \text { C } 2.2 \\
42 \text { C } 2.3\end{array}$ & $\begin{array}{l}0 \\
0 \\
0\end{array}$ \\
\hline $\begin{array}{l}42 \text { C } 3.1 \\
42 \text { C } 3.2 \\
42 \text { C } 3.3\end{array}$ & $\begin{array}{l}0 \\
1 \\
0\end{array}$ \\
\hline Total & 100 \\
\hline
\end{tabular}

